\title{
Transposição do olhar: notas sobre a teoria da adaptação
}

\author{
Saulo Lopes de Sousa ${ }^{\mathrm{i}}$ \\ Deivanira Vasconcelos Soares ${ }^{\text {ii }}$
}

\section{RESUMO}

O artigo se propõe a revisar criticamente uma amostra bibliográfica de estudos teóricos referentes ao complexo âmbito da adaptação, seus intercursos e meandros, a fim de sondar as características e os processos do fazer adaptativo, bem como refletir sobre a espinhosa questão da fidelidade. É possível se pensar o traslado da literatura para a imagem-som não como simples enquadramento/adequação de um código a outro, mas como uma transposição, pensada como arranjos ou adaptações de gêneros, portanto promotora de significados. À guisa de exercício analítico, toma-se um recorte da minissérie Dois irmãos (2017), de Luiz Fernando Carvalho, em diálogo com o romance homônimo de Milton Hatoum (2006), para se pensar os expedientes da liberdade criadora no exercício da adaptação.

Palavras-chave: Literatura; Teoria da adaptação; Fidelidade.

\begin{abstract}
The article proposes to critically review a bibliography sample of theoretical studies concerning to the complex scope of adaptation, its interchanges and meanders, in order to probe the characteristics and processes of adaptive making, as well as to reflect on the thorny question of fidelity. It is possible to think of the transfer of literature to the image-sound not as a simple framing/adaptation from one code to another, but as a transposition, thought as arrangements or adaptations of genres, thus promoting

\footnotetext{
${ }^{i}$ Doutorando em Estudos de Literatura pela Universidade Federal do Rio Grande do Sul (UFRGS). Mestre em Letras pela Universidade Estadual do Maranhão (UEMA). Especialista em Estudos Linguísticos e Literários pela Universidade Estadual do Piauí (UESPI), Campus Torquato Neto (Teresina). Graduado de Letras/Literatura pela Universidade Estadual do Maranhão (UEMA). Pesquisador do Grupo de Estudos Literários e Imagéticos (GELITI/UEMASUL). Atualmente, é professor efetivo de Língua Portuguesa no Instituto Federal do Maranhão (IFMA/Campus Açailândia). ORCID: https://orcid.org/0000-0001-6290-5954 | saulo.sousa@ifma.edu.br

ii Mestra em Letras (área de concentração: Teoria literária) pela Universidade Estadual do Maranhão (UEMA), Campus São Luís. Especialista em Metodologia do Ensino Superior pelo Centro Mesquita de Educação Superior (INESPO). Licenciada em Letras - Literaturas de Língua portuguesa pela Universidade Estadual do Maranhão (UEMA). Pesquisadora do Grupo de Estudos Literários e Imagéticos (GELITI/UEMASUL). Atualmente, é professora substituta da Universidade Federal do Maranhão (UFMA).

ORCID: http://orcid.org/0000-0001-9333-3549|dv.vasconcelos@hotmail.com
} 
meanings. As an analytical exercise, it takes a snapshot of the miniseries Dois irmãos (2017), by Luiz Fernando Carvalho, on dialogue with the novel at the same name by Milton Hatoum (2006), to think about the expedients of creative freedom in the exercise of adaptation.

Keywords: Literature; Theory of adaptation; Fidelity.

Tudo se recria e o instante Varia de ângulo e face Segundo a mesma vidaluz Que instaura jardins na amplitude [...]

(FONTELA, 2006, p. 11)

\section{TRAZENDO À LUZ A QUESTÃo}

As adaptações existem em grande quantidade, desde o final do século XIX ${ }^{1}$. Sabe-se, também, que desde seu vertedouro, espinhosos debates convergiram para a questão da fidelidade para com a obra referência ou o julgamento de valor, muito embora já se tenha superado essas contendas teóricas por volta da década de 1960. Antes disso, coexistiram opiniões que declaravam a adaptação (enquanto gênero criativo-interpretativo) inferior à fonte ou responsável por uma eventual subtração/abreviação da natureza da obra adaptada. Por outro lado, as teorias contemporâneas da adaptação (e da tradução) já postulam, com considerável firmeza, a autonomia e a especificidade do fazer adaptativo,

Kristeva (1971, p. 146), ao formular a gênese do processo de criação literária, postula que "todo texto é absorção e transformação de outro texto". No seio dessa perspectiva - aliás, inspirada no dialogismo de Bakhtin - repousa a noção de convergência discursivo-textual, isto é, as relações que um texto estabelece com textos outros, coletados em experiências linguísticas anteriores. Pode-se dizer, então, que a adaptação é um fenômeno possível graças à abertura que a obra literária, naturalmente, dá às relações com outros textos, como também a outras matizes de expressão. Literatura e adaptação operam modos distintos de funcionamento.

O colóquio em torno da fidelidade rigorosa de uma adaptação à obra primeira foi notoriamente erigido por Stam (2008), para o qual pretensa obrigatoriedade se mostra 
pouco provável, por haver no método de adaptação a mudança de linguagem. O autor, justificando tal remota possibilidade, resgata princípios basilares dos estudos comparatistas:

\footnotetext{
A intertextualidade de Kristeva, com raízes no "dialogismo" de Bakhtin, enfatizou a interminável permutação de traços textuais, e não a "fidelidade" de um texto posterior em relação a um anterior, o que facilitou uma abordagem menos discriminatória. (STAM, 2008, p. 20)
}

Compreende-se que o fator intertextual é o aspecto responsável pela recuperação de traços característico da obra original, contudo abrindo espaço para que coabitem consigo elementos novos oriundos do imaginário criativo do produtor. Stam postula a "herança" de constituintes estéticos que as unidades de imagem e som recrutam para o constructo do produto da adaptação. A imagética aciona elementos pictórios e visuais; a acústica, recursos musicais, do diálogo e experimentos sonoros. Todos esses intertextos, congregados, expandem a envergadura do texto-base, convergindo, assim, para o desvelar de múltiplos significados: "O dialogismo intertextual, portanto, auxilia-nos a transcender as aporias da "fidelidade"” (STAM, 2008, p. 21).

Em Kristeva, Stam capta resvalos do postulado de Bakhtin e visualiza a rede intensa de trocas intermináveis de matérias textuais, muito distante, por isso, da intenção de fidelidade de um texto derradeiro em relação a outro prévio. De Bakhtin, irá perceber a categoria de autor como administrador de discursos preexistentes, o que possibilita o questionamento da "originalidade" no fazer artístico. Assim posto, pela concepção bakhtiniana, Stam compreende a literatura como uma construção híbrida, na qual estão presentes diferentes vozes.

Centrando-se na hipertextualidade enfocada por Genette, Stam considera as adaptações como "hipertextos nascidos de hipotextos preexistentes, transformados por operações de seleção, ampliação, concretização e realização" (STAM, 2008, p. 22). A solução encontrada para se tomar a adaptação pelo ângulo do dialogismo intertextual não descarta, entretanto, os preceitos de valor, embora seja menos arraigada à hierarquização e à taxação moralista. Nesse sentido, a adaptação pode ser analisada com base nos entremeios dialógicos e intertextuais que incidem sobre o relacionamento texto/imagem/som, sempre fruto de uma leitura, de uma interpretação, de uma recriação. 
Há de se cogitar, em contrapartida, que o propósito intertextual de uma adaptação possuirá maior ou menor grau de explicitude, a depender da visão pessoal de seu realizador. Sanders (2006), a esse respeito, identifica um segundo movimento interpretativo do texto-fonte: as apropriações. Para a estudiosa, uma apropriação conserva sua relação intertextual com a obra de partida de forma mais imbuída, velada, operando uma espécie de distanciamento para com o original. Nesse particular, o afastamento sinaliza, dentre outros fatores, os olhares novos e as perspectivas originais oriundos desse esforço criacionista, uma vez que abdica da replicação daquilo que na matriz é intrínseco para responder a um compromisso de ordem pessoal. Em todo o caso, “adaptação e apropriação estão inevitavelmente envolvidas na performance de eco e alusão textual, mas isso geralmente não equivale à bricolagem fragmentária de citações mais momentaneamente entendida como o modo operativo da intertextualidade" (SANDERS, 2006, p. 4, tradução nossa) ${ }^{2}$.

Nessa perspectiva postulada por Sanders, serve como exemplificação o filme Veja esta canção (1994), de Carlos Diegues. Nesse audiovisual, contam-se quatro histórias baseadas em músicas de compositores brasileiros e, em um exercício de apropriação, a narrativa cinematográfica é regada com trechos das canções, abeirandose de amores diversos em ligação temática com as letras de Jorge Benjor, Caetano Veloso, Gilberto Gil e Chico Buarque. Nesse mesmo perfil, a minissérie brasileira Amor em quatro atos (2011), dirigida por Roberto Talma, se inspira em canções de Chico Buarque em um processo criativo que corrobora a interpretação mais velada do texto de origem. Assim, criar um audiovisual a partir de letras de canções, textos de estruturas poéticas e sem um encadeamento narrativo será, para bem entender, um ato de apropriação, de embebecimento criativo que interpreta e cunha um intertexto outro.

Trazer luz aos específicos intercursos da adaptação revela, por assim dizer, uma nova postura de tratamento desse fenômeno e possibilita cotejá-lo em sua autenticidade. Não seria suficiente, portanto, o stricto julgamento de valor em comparativo aos textos literários originais. Ao contrário, como aponta Leitch (2007), o salutar dessa abordagem comportaria, também, o conhecimento da própria literatura, dos mecanismos textuais de operação desse sistema que, igualmente, partem de uma especificidade. Tal conjectura, na opinião do crítico, dissolveria de vez a imbricada alegação valorativa e as amarras da fidelidade, trazendo novo fôlego aos estudos de adaptação: 


\begin{abstract}
Para revitalizar o estudo da adaptação, precisamos reformular a presunção que mesmo a mais superficial consideração desse problema nos impõe - os textos de origem não podem ser reescritos - como uma nova suposição: os textos de origem devem ser reescritos; não podemos deixar de reescrevê-los. (LEITCH, 2007, p. 16, tradução nossa) ${ }^{3}$
\end{abstract}

Leitch (2006), portanto, observa que o ato da escrita jamais será uma prática inaugural, originária e incólume, pois sua realização prescinde o fundamento linguístico obtido pela atividade da leitura: só se escreve a partir daquilo que se conhece. Adaptar, por esse viés, surge, propiciamente, como selo da constatação de que "[...] literatura cria outras literaturas" (SANDERS, 2006, p. 14, tradução nossa) ${ }^{4}$. Ao contrário da palavra referencial, cotidiana e facilmente solúvel, a palavra literária é insuflada a ser fênix, que renasce das próprias cinzas, vindo a ser infinitamente aquilo que acabara de ser.

\title{
ESPECIFICIDADE: ADAPTAÇÕES POR ELAS MESMAS
}

Diniz (1999) propõe que a análise da especificidade na adaptação deve atingir horizontes mais amplos, ao entender que o objetivo de seu estudo é alcançar, por assim dizer, as práticas discursivas inerentes aos textos que fundamentam a constituição da adaptação, atreladas ao contexto de produção com seus respectivos valores (sociocultural, político, econômico, ideológico etc.). Tal preocupação, conforme a autora, tem como finalidade avaliar o modo de realização da prática adaptativa, bem como a justificativa das escolhas pelas quais aquela prática ocorreu:

A tarefa do pesquisador será, portanto, partir das práticas discursivas do filme, e, em seguida, voltar-se para práticas ou situações contextuais, que funcionam como modelos. Finalmente, procurar marcadores que indiquem as relações intertextuais e intersistêmicas. (DINIZ, 1999, p. 43)

Por outro lado, Chartier (1999) considera a multimídia um fenômeno contemporâneo. Com efeito, a difusão do texto, antes feita pela materialidade tipográfica dos livros, agora se dá mediante a diversidade de formas particulares que a obra pode assumir. Como bem conhecemos, o meio digital é, hoje, responsável pela produção e disseminação de múltiplas modalidades textuais, transpassadas por diferentes recursos virtuais que inserem a obra escrita na realidade eletrônica. Em face 
dessa "vitrinização" do texto e dos modos de difusão, o ato adaptativo multimidiático "[...] conduz à produção de uma entidade, de uma obra com traços específicos, que não são aqueles das formas materiais em que ela se encarna" (CHARTIER, 1999, p. 70).

Enquanto experiência cultural inserida no bojo das relações interartísticas, nas quais a obra adquire uma multiplicidade de formas, a ponto de imergir no que Chartier denomina "processo de desmaterialização", a adaptação impulsiona o desmantelamento da cristalizada hierarquização da categoria literária libresca. Com tal irrupção, tem-se por intuito a abertura da polivalência modal característica dessa recente midialidade eletrônica, que modifica até mesmo os rumos de concepção e dispersão da obra. Chartier entende, assim, que o fluxo de categorias leva em conta a posição do leitor, a circunstância de recepção e o suporte assumido pelo texto. Em todo o caso, é irrealizável a equiparagem de uma mesma obra em diferentes formas, uma vez que "A obra é jamais a mesma quando inscrita em formas distintas, ela carrega, a cada vez, um outro significado" (CHARTIER, 1999, p. 71).

Com as contribuições teóricas de Hutcheon (2013), continua-se a pensar uma teoria da adaptação, naquilo que a torna um processo artístico, autônomo e, por isso, passível de ser avaliado de forma independente das "fontes". O posicionamento da autora atesta a atitude de tomar as adaptações como adaptações, dispensando, com efeito, a ligação umbilical requerida pela crítica para creditar-lhe existência válida. Aliás, alcançar seu próprio núcleo significativo, constitui, para Hutcheon, a natureza da adaptação (cf. HUTCHEON, 2013, p. 25).

Emanando ecos da transtextualidade de Genette, a estudiosa observa que, no panorama dos estudos da adaptação, o preceito hipertextual desponta como pedra basilar desse processo:

\footnotetext{
Trabalhar com adaptação como adaptação significa pensá-las como obras inerentemente "palimpsestuosas", [...], assombradas a todo instante pelos textos adaptados. Se conhecemos esse texto anterior, sentimos constantemente sua presença pairando sobre aquele que estamos experienciando diretamente. Quando dizemos que a obra é uma adaptação, anunciamos abertamente sua relação declarada com outra(s) obra(s). (HUTCHEON, 2013, p. 27)
}

Porém, a autora esclarece que tal anúncio de sintonia entre adaptação e obra adaptada, de longe, sinaliza a eleição de um código minimizador da validade estética da 
adaptação, que lhe destituiria, portanto, de sua autenticidade. Em verdade, é esse aspecto dual da adaptação - apontar para outra(s) obra(s), na sua especificidade - que torna possível teorizá-la como adaptação.

Pelo exame da construção de sua teoria, a pensadora aborda o trabalho adaptativo sob três molduras: 1) uma entidade ou produto formal; 2) um processo de criação e 3) processo de recepção. Enquanto entidade ou produto formal, a adaptação trilha a vereda da transposição ou transcodificação, como pode ainda evidenciar um deslocamento de foco e, por isso, contextual. Sendo processo de criação, tem-se implícito o esforço de (re)interpretar e (re)elaborar a obra de partida, posto que a "repetição" incorpora nuances condizentes com os propósitos e instrumentos presentes na reinvenção. Finalmente, como processo de recepção, a adaptação se reveste com a couraça intertextual, palimpsestuosa, a partir da qual aciona memórias de obras anteriores que a atravessam e a constituem (cf. HUTCHEON, 2013, p. 29-30).

Com base nessas perspectivas, Hutcheon clarifica, em um sentido mais estrito, as possibilidades de se compreender a adaptação, elencando três modos de engajamento, ou seja, afinidades mantidas entre o público e a obra de arte:

[...] o modo contar (um romance) nos faz mergulhar num mundo ficcional através da imaginação; o modo mostrar (peças e filmes) nos faz imergir através da percepção auditiva e visual [...]; o modo participativo (videogames) nos faz imergir física e cinestesicamente [...] geralmente chamado "interativo". (HUTCHEON, 2013, p. 47-48, grifos nossos)

Tais formas de relacionamento do espectador com as narrativas escritas ou audiovisuais, para Amorim (2013), são preponderantes ao escopo de se abranger com mais nitidez as sutilezas de cada plataforma midiática, como também suas competências para transmitir histórias. Assim, o transporte de um modo a outro é fundamental para a apreensão da dinâmica do ato adaptativo (cf. AMORIM, 2013, p. 23).

Hutcheon conclui, então, que a adaptação - enquanto processo e produto inevitavelmente mantém perceptíveis sintonias com a obra que adapta, todavia sustenta em si independência semântica a ponto de converter-se numa obra autônoma. Em resumo, quebrantam-se as aporias do "parasitismo":

A adaptação não é vampiresca: ela não retira o sangue de sua fonte, abandonando-a para a morte ou já morta, nem é mais pálida do que a obra adaptada. Ela pode, pelo contrário, manter viva a obra anterior, dando-lhe 
uma sobrevida que esta nunca teria de outra maneira. (HUTCHEON, 2013, p. 234)

Assim balizados, os teóricos em relevo abraçam o ponto de vista a partir do qual as amarras da fidelidade não sustentam ancoradouro, posto que no processo de transposição da palavra para a imagem, além do trânsito de código sêmico, ocorre inserção/exclusão de elementos, sujeitos "[...] não apenas às necessidades de gênero e mídia [...], mas também ao temperamento e talento do adaptador, além de seus próprios intertextos particulares que filtram os materiais adaptados" (Ibidem, p. 123). Por assim dizer, tanto o romance como o filme coexistem em independência semântica, o que não impede, obviamente, que se estabeleça uma leitura aproximativa de diversas gradações.

\section{OLHANDO AS ADAPTAÇÕES DE PERTO}

Mediante a cena teórica exposta, Stam oferta um traçado salutar a respeito de algumas questões pertinentes à teoria e prática da adaptação. Seu propósito reside na apresentação de uma abordagem menos depreciativa e mais centrada em suportes e instrumentos que viabilizem a compreensão da especificidade dialógica e intertextual da adaptação. Por esse motivo, mencionamos algumas dessas questões no quadro a seguir. 
Quadro 1: Questões acerca do âmbito da adaptação

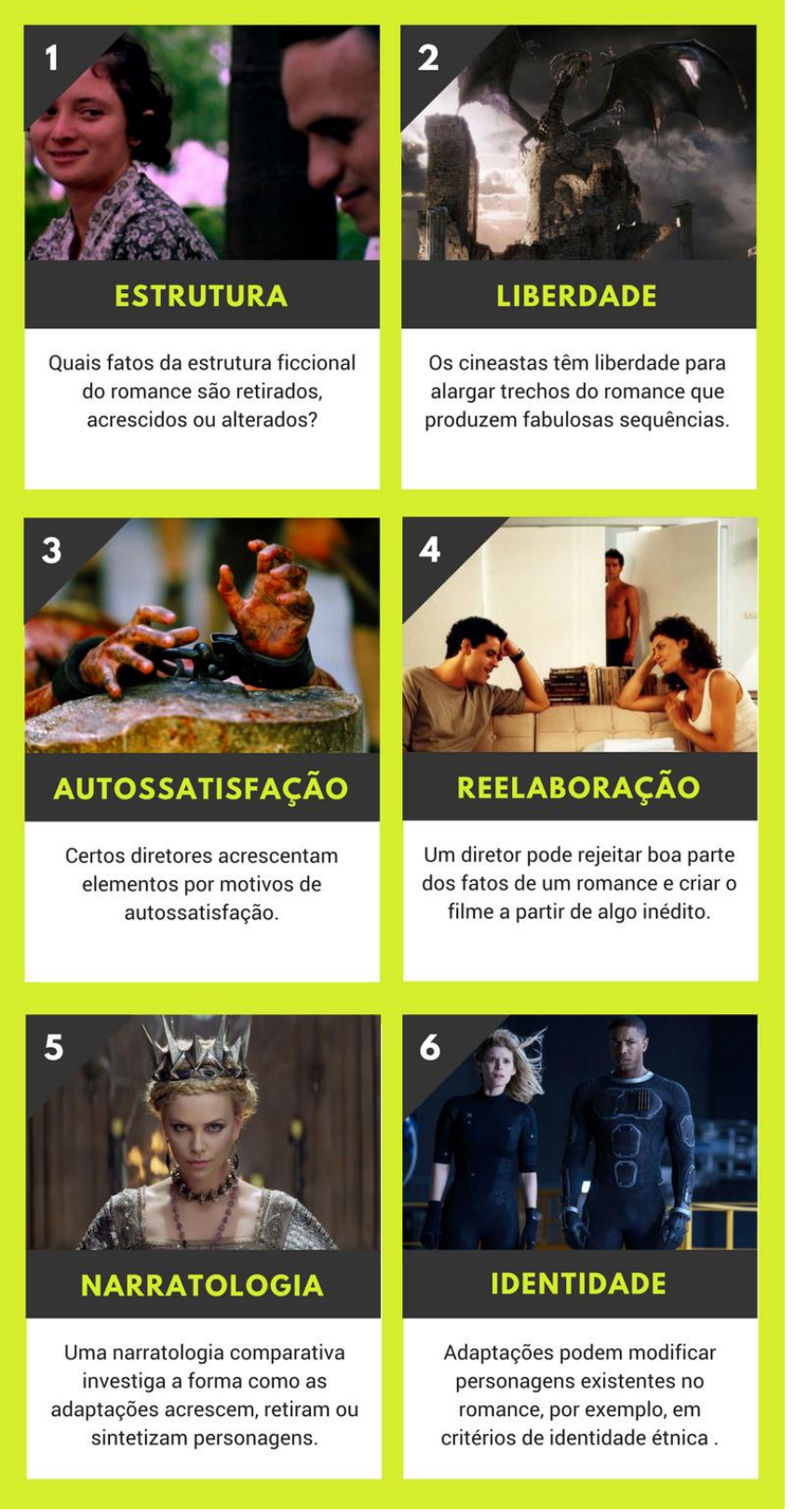

Fonte: cf. STAM, 2006, p. 39-415

Como ilustrativo da primeira questão, cita-se o filme $A$ hora da estrela (1985), dirigido por Suzana Amaral, cujo roteiro é adaptado da novela homônima de Clarice Lispector. A obra da escritora se estrutura a partir do discurso metalinguístico do narrador Rodrigo S.M., atado ao penoso ofício de contar a história de sua personagem, a retirante nordestina Macabéa. Para a transposição cinematográfica, Suzana decidiu 
omitir a figura narrativa, escolha que, por sua vez, remanejou a lida com o caráter subjetivo que subjaz o processo criativo do texto clariceano.

Dado que a performance de Rodrigo S.M. possui fundamental relevância na narrativa, a cineasta buscou na própria linguagem cinematográfica recursos equivalentes à função do narrador, tais como movimentos de câmera, enquadramentos, articulação de planos, trilha sonora, efeitos metafóricos. Uma vez que, na prosa de Clarice, é Rodrigo o ponto de convergência, Suzana Amaral justifica sua supressão no filme pela intenção de enfatizar a personagem Macabéa, a quem, de fato, devam incidir os olhares:

\begin{abstract}
O eixo central foi mantido: "as tristes aventuras de uma moça na cidade grande, toda voltada contra ela". No livro, o narrador é o personagem principal, que na verdade é a própria Clarice. Eliminei o narrador porque eu queria que a personagem principal fosse a Macabéa, personagem que não age, é "agida" pelas circunstâncias. (AMARAL, 2003)
\end{abstract}

No segundo caso, o filme Alice no país das maravilhas (2010), do diretor Tim Burton, baseado no clássico infantil escrito por Lewis Carroll, é um bom exemplo de liberdade criativa. Diferentemente do que se narra no romance de Carroll, e também na adaptação feita em 1951 pelos Estúdios Walt Disney, há no filme o Glorian day, conforme previsto num oráculo: trata-se da batalha entre a personagem Alice, representando a campeã da Rainha Branca, e o Jaguadarte, dragão e espécie de alter ego da Rainha Vermelha. Ambos lutam para decidir qual majestade governaria o país das maravilhas. Única capaz de empunhar a espada Vorpal, Alice consegue abater a fera e coroar a Rainha Branca com a governança do reino subterrâneo, destinando ao exílio a Rainha Vermelha e o Valete de Copas.

Sobre o item da autossatisfação, o efeito visual "ponto de vista de Deus", no filme A Paixão de Cristo (2004), de Mel Gibson, mostra o desejo do diretor em criar essa tomada a partir de uma inspiração obtida ou, como ele mesmo afirma, "uma visão muito especial". A direção de arte capturou cenas da crucificação no alto de uma colina, de um guindaste a 45 metros de altura. Nos estúdios de produção, construíram um cenário em miniatura e o filmaram. Montaram, por fim, as duas tomadas, e acrescentaram a lágrima por computação gráfica, de modo que a "gota se formasse direto na imagem e se separasse dela" (GIBSON, 2004). O conceito produz no espectador a dúvida quanto à natureza da gota d’água, se se trata de um pingo de chuva ou, realmente, da lágrima de Deus. 
O filme Dom (2003), de Moacyr Goés, pode ser encaixado na quarta questão, ao propor uma leitura livre e inspirada do romance Dom Casmurro. O roteiro do filme segue um caminho de construção da trama bem diferente do enredo original. A manutenção do diálogo com a obra machadiana é sustentada por algumas características referenciais ao livro que são transferidas aos dias atuais: o triângulo amoroso dos protagonistas, o amor de infância, o casamento, o ciúme doentio do amigo, a suspeita do adultério da esposa e a citação explícita ao romance de Machado na história. Contudo, o diretor resolveu aplicar um tom menos denso no tratamento da trama, distante do que é primordial na escritura narrativa de Machado, escolha que amenizou as complexas relações entre os personagens que são observadas no livro. Conforme Góes (2003), a ideia da produção fílmica era homenagear o escritor, com o intento de fazer "um filme que se comunique com o público", sem a pretensão de gravar "um filme-filme, que tivesse um pé na metalinguagem".

O conto de fadas dos Irmãos Grimm, Branca de Neve, é adaptado no filme Branca de Neve e o Caçador (2012), com direção de Rupert Sanders, e exemplifica o quinto ponto, pois sintetiza potencialmente a carga de invídia e crueldade que caracteriza a personagem da madrasta má, papel desempenhado pela atriz Charlize Teron. A começar pelos colossais poderes mágicos, como a capacidade de sugar a beleza e a jovialidade de outras mulheres e de se metamorfosear (em corvo, por exemplo). Na narrativa infantil, a personagem apenas se disfarça de uma velha senhora para realizar seu plano malévolo de assassinar a enteada. Há de se mencionar que, paralelamente ao projeto de Sanders, outra adaptação cinematográfica da fábula dos Grimm era produzida. Espelho, Espelho meu (2012), do diretor Tarsem Singh, se constitui numa variante humorada da história, cuja vilã, interpretada pela atriz Julia Roberts, está mais caracterizada por toques de comicidade combinados a burlescas artimanhas para atingir seus objetivos.

Um exemplo da mudança étnica de personagens apontada pelo sexto item aparece no filme Quarteto Fantástico (2015), dirigido por Josh Trank, baseado nas histórias em quadrinhos da Marvel Comics. A personagem Tocha Humana, originalmente caucasiana nos quadrinhos, é interpretada pelo ator negro Michael B. Jordan. Nas duas versões anteriores - Quarteto Fantástico (2005) e Quarteto Fantástico e o Surfista prateado (2007) - a personagem foi vivida pelo ator branco Chris Evans. 
Ainda sobre modificação de personagens da Marvel na transposição para o universo cinematográfico, o filme Doutor Estranho (2016), dirigido por Scott Derrickson, teve o Ancião, um velho místico tibetano, interpretado por uma mulher, a atriz britânica Tilda Swinton.

Todos os tópicos elencados se direcionam à constatação do desenho específico adotado pela adaptação, salvaguardada a possibilidade de o adaptador empreender um trabalho criativo no tratamento do material literário, explorando, com isso, suas potencialidades de significação. Dessa forma, um portal para a aventura da adaptação se abre com vistas à sua forma inteiriça, isto é, não dependente dos ecos do texto literário para afirmação enquanto tal.

\section{UM CASO MAIS ESPECÍFICO}

Deslocar uma estrutura narrativa repleta de sinuosidades, como é o romance, para um circuito imagético requer do adaptador intenso trabalho criativo, pois o produto audiovisual propõe as imagens que o leitor deveria criar em sua mente, no ato da leitura. As construções imagéticas são apresentadas espontaneamente ao espectador, ao contrário do que ocorre com a literatura, na qual é o leitor quem deve criá-las, o que também não significa que as imagens não precisem ser lidas para fazerem sentido. Nesse particular, Hutcheon deposita a maior complexidade da execução do processo adaptativo na prosa romanesca: "A conhecida mudança do contar para o mostrar - e, mais especificamente, de um romance longo e complexo para qualquer forma de performance - é geralmente vista como a mais angustiante das transposições" (HUTCHEON, 2013, p. 64).

Fica a cargo do adaptador, portanto, comandar todas as articulações de maneira harmônica. A nível de ilustração, tem-se a minissérie Dois irmãos ${ }^{6}$ (Fig. 3), de Luiz Fernando Carvalho, na qual o diretor consegue produzir efeitos bastante dramáticos e sensíveis, mesclando tensão e força emotiva. Esse é mais um caso que se encaixa na questão de "liberdade" criadora proposta por Stam (2006): a reconfiguração do objeto literário no novo código sêmico implica nas escolhas e estratégias de (re)criação do adaptador, uma vez que o sistema acolhedor deve possibilitar a realização ou representação da obra anterior. 
A fim de se perceber o esforço do diretor em (re)interpretar e (re)elaborar a obra original, incorporando nuances condizentes com os propósitos e instrumentos dessa reinvenção, o olhar analítico sobre a minissérie toma por base o princípio da mise-enscène $e^{7}$, a partir da teoria cinematográfica de Bordwell (2008), para se pensar os expedientes ficcionais: "A cada momento, em grande parte do cinema narrativo, a ficção é orquestrada para nosso olhar pela encenação cinematográfica, que é construída para informar, manifestar ou simplesmente encantar visualmente. Somos afetados e não percebemos" (BORDWELL, 2008, p. 29).

Uma sequência da minissérie que se coaduna à tal perspectiva é a morte da personagem Halim, cujo trecho, no romance, é reproduzido a seguir:

\footnotetext{
Nós o esperamos até tarde da noite. Minha mãe e eu no nosso quarto dos fundos. Rânia e Zana no andar de cima, deitadas, com a porta aberta, atentas a qualquer ruído. Deram duas horas e nada do Halim chegar. Por volta das três escutei o ronco de minha mãe, quase um assobio grave, um sopro. Um nambuaçu piou por ali; olhei para o chão do quintal, nem sombra da ave. Depois reconheci o canto de um anum, me senti melancólico, mareado. As copas escuras cobriam os fundos da casa. Um barulhinho esquisito riscava a noite, podia ser mucura faminta no faro de um poleiro ou morcegos mordendo jambo doce. Lembro que as palavras do livro que eu lia foram se apagando e sumiram. O livro também foi engolido pela escuridão. Cochilei, debruçado na mesinha. Lá pelas cinco da manhã (ou um pouco depois, porque o cortiço dos fundos já emitia sinais de despertar e a noite começava a perder sua treva), um ruído me despertou. Vi uma claridade na cozinha e logo depois um vulto. Era uma mulher. A mão de Zana surgiu, aclarada por uma luz de vela. Ela saiu devagarinho, segurando um alguidar, a vela perto da escada. Parou, virou a cabeça e deu um grito medonho. $\mathrm{O}$ alguidar estilhaçou no assoalho, a vela tremia-lhe na mão. Domingas saiu do sonho e pareceu mergulhar num pesadelo: seu rosto sonolento virou uma máscara assustada. Nós dois nos aproximamos da sala: Halim estava ali, de braços cruzados, sentado no sofá cinzento. Zana deu um passo na direção dele, perguntou-lhe por que dormira no sofá. Depois, menos trêmula, conseguiu iluminar seu corpo e ainda teve coragem de fazer mais uma pergunta: por que tinha chegado tão tarde? Então com o sotaque árabe, gritou o nome dele, já lhe tocando o rosto com as duas mãos. Halim não respondeu.

Estava quieto como nunca.

Calado, para sempre. (HATUOM, 2006, p. 106)
}

Bordwell aponta para a necessidade de se observar as sutilezas e linhas mais tênues que tornam a encenação cinematográfica uma etapa importante do ofício ficcional. A montagem aciona no espectador a sensação de continuidade narrativa, enquanto que a encenação - que o autor relaciona explicitamente à mise-en-scène descortina o corpo da ficção materializado no filme. Ela também sinaliza as escolhas pelas quais opta o diretor para efetivar sua leitura do roteiro. 
Na cena supracitada da minissérie, temos Halim (Antônio Fagundes), que regressa ao lar, após alguns dias sumido. Entrando em casa, senta-se no sofá da sala, degusta seu narguilé ${ }^{8}$ e, ao rememorar os felizes momentos que viveu ao lado de sua esposa Zana (Eliane Giardini), falece de súbito mal-estar. A matriarca, a princípio, alegra-se pelo regresso do companheiro, mas ao aproximar-se, constata que o marido está morto e entra em desespero. Logo, os demais habitantes da casa surgem na sala Rânia (Bruna Caram), sua filha, a empregada Domingas (Sílvia Nobre) e seu filho, Nael (Irandhir Santos), todos consternados com a situação trágica. Destoante da atmosfera lutuosa, Omar (Cauã Reymond), o gêmeo rebelde, irrompe a cena com aparente indiferença pela morte do pai e, num ataque bravio de fúria, agarra-se ao corpo de Halim, agitando-o aos solavancos. Todos tentam separá-los, enquanto Zana lamenta, dolorosamente, a perda de seu grande amor.

Notamos que há poucos cortes de cena, pois predomina na sequência a posição de câmera localizada atrás do sofá onde se encontra o corpo de Halim (Fig. 1). Assim, as mudanças de planos ocorrem nas entradas dos atores na cena. A escolha pela prevalência do ponto de vista posterior, focalizando frontalmente as personagens em primeiro plano, alude à captura da tensão emocional que emerge à derme ante o infortúnio da notícia. É também o olhar do espectador que presencia o desaguar dramático da família.

Figuras 1 (a. b. c.): Focalização da câmera
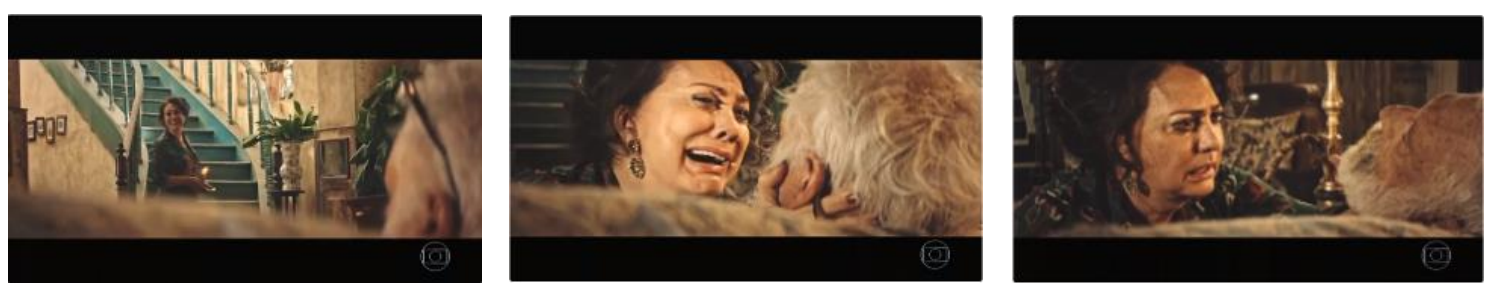

Fonte: Frames da Minissérie Dois Irmãos (2017)9.

Os enquadramentos fechados nos rostos de Zana e Omar, assim como a coreografia repleta de movimentos ora contidos, ora impetuosos, confluem dois polos: a contrição de Zana e sua família, ao saberem do falecimento de Halim, e a revolta violenta e inflamada de Omar. Tal contraste se reflete na própria ocasião em que se dá a morte: Natal, data comemorativa do natalício de Jesus Cristo, como atesta a árvore natalina posta à sala e uma faixa pendurada na parede com o dito "Feliz Natal". 
Paradoxalmente, no lugar da celebração da vida e do nascimento, tem-se o motivo lúgubre da reunião.

Também dois elementos cenográficos pontuam, sutilmente, o tom trágico da narrativa (Fig. 2). O relógio na parede, de início, metaforiza o tempo rememorado das boas lembranças de Halim com seus amigos e companheira, mas também representa a linha vital de Halim prestes a se romper. Assim, o objeto reúne as três dimensões temporais que circunda a casa: o recordar do passado por Halim, o findar do presente de seu viver e o instaurar do futuro desventurado que sua morte causa à família libanesa. Em segundo lugar, os óculos de Halim caídos, que já não adquirem serventia, haja vista os olhos de seu dono terem se fechado para não mais enxergarem. Para Zana, eles representam uma visão clara e consciente da morte do esposo, pois, até então, seus olhos estavam embaçados pelas lágrimas de espera por seu regresso e pela contente ilusão de avistá-lo “dormindo" no sofá, quando, na verdade, se encontrara defunto. Sem as lentes, pode ela ver com maior nitidez aquilo que se tornou sua maior tristeza.

Figuras 2 (a. b.): O relógio e os óculos
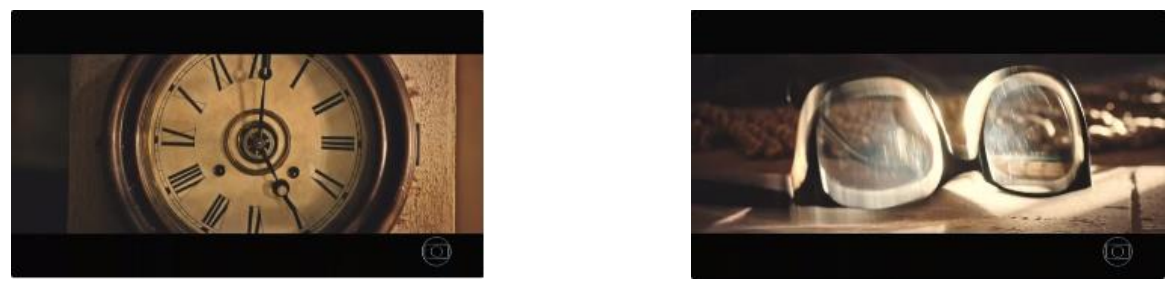

Fonte: Frames da Minissérie Dois Irmãos (2017).

No plano sonoro, cabe assinalarmos sons das engrenagens do relógio como que um portal onde se dá a passagem do tempo atual à temporalidade da memória. Em seguida, as recordações de Halim são embaladas por uma canção que mistura blues com valsa romântica, que levam o personagem a bailar com as reminiscências de Zana, ainda jovem, e seu pai Galib no restaurante Biblos, bem como das rodas de conversas com seus amigos e de sua festa de casamento. Um corte abrupto acontece por um flash fosforescente de uma câmera fotográfica, e tem-se a imagem de Halim, de costas, na ponta da canoa, enquanto Nael narra o anúncio fatídico: "Halim estava quieto, como nunca, calado para sempre".

Em seguida, a imagem retorna ao sobrado e mostra Zana dirigindo-se à escada, enquanto o toque do relógio faz saber das horas. A câmera focaliza frontalmente o 
corpo de Halim no sofá, quando se ouve um forte e seco badalar, que alegoriza, sem dúvida, a comunicação de sua morte. Então, após a queda dos óculos, surge uma banda de som orquestral, destacando a melodia lenta e introspectiva de violinos, que, sem dúvida, acentua o contexto dramático da cena e reverbera os sentimentos dolorosos da recém-viúva. No romance de Hatoum, ela é assim narrada:

[...] Logo que desceu a escada, Omar não entendeu, não queria entender o que acabara de acontecer. Viu no sofá cinzento o único homem que o desonrou com um bofete. Começou a gritar, criança incendiada de ódio ou de algum sentimento parecido com o ódio. Gritava, fora de si: "Ele não vai acorrentar o filho dele? Não vai passar a mão no rosto suado? Por que ele não se mexe e fala comigo? Vai ficar aí, com esse olhar de peixe morto?" (HATOUM, 2006, p.162).

[...] Omar nos surpreendeu com seu gesto irado, o dedo em riste apontado para o rosto de Halim, para os olhos quase fechados, sem vida, do pai cabisbaixo. Rânia ficou paralisada: não sabia o que fazer, não pôde impedir o irmão de gritar, de pegar no queixo do pai e erguer-lhe a cabeça. [...] Fiz um gesto para Talib e suas filhas, expulsei o Caçula da sala e arrastei-o até o quintal. (HATOUM, 2006, p. 163)

$\mathrm{Na}$ minissérie, quando da entrada de Omar em cena, o som dos violinos ganha peso e gravidade ascendente, e cria tanto na imagem quanto no espectador um estado tensivo de aflição, sobretudo quando Omar explode sua ferocidade áspera e animalesca sobre o corpo do pai (Fig. 3). Só quando conseguem arrancá-lo do recinto é que se pode ouvir um fundo musical tipicamente libanês, cuja voz feminina entoa uma espécie de ária lacrimosa e cortante, que palmilha os instantes de despedida de Zana com seu falecido marido.

Figuras 3 (a. b. c.): Fúria de Omar
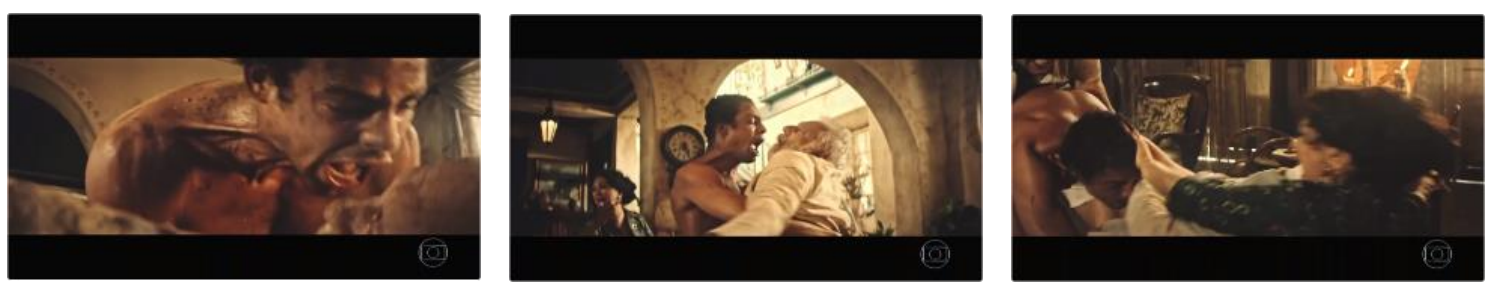

Fonte: Frames da Minissérie Dois Irmãos (2017).

O interessante da proposta de visibilizar a encenação cinematográfica gira em torno da confecção de nuances expressivas e de significado que se instalam no interior da imagem e que são fugidias à observação do espectador. Então, o ângulo da mise-en- 
scène se avizinha duma dimensão mais poética, quando também conclama a experiência do espectador no despertar de "[...] sua sensibilidade às imagens moventes, aumentando sua capacidade de apreender tanto a inovação técnica quanto a experimentação inteligente dos artistas envolvidos (BORDWELL, 2008, p. 32 e 40).

Sintonizados, todos os elementos de composição do quadro, além de conservarem suas cargas de significado, potencializam a atuação/interpretação dos atores que, de modo praticamente visceral, desnudam as ruínas e os conflitos familiares das personagens. Por esse motivo, o ensaio ${ }^{10}$ se evidencia, exemplarmente, como favorecedor da encenação, pois nele os atores mentalizam que aspectos da mise-enscène devem encontrar para representar de maneira espontânea a narrativa nos planos e enquadramentos. Isso, sem dúvida, acrescenta à filmagem, que se desenrola mais fluída, natural e orgânica, e permite que os intérpretes criem movimentos e atitudes que, em vez de entravar a história, se tornam inerentes a ela. Em suma, “[...] a encenação pode guiar nossa atenção dentro de um campo visual complexo, brincar de esconde-esconde com nossas expectativas, congregar atributos como delicadeza ou vitalidade e agenciar uma modalidade de narrativa mais inovadora" (BORDWELL, 2008, p.40).

No caso da minissérie Dois Irmãos, o fulgor interpretativo do ator Cauã Reymond, na pele de Omar, abre fendas para que ele cometa alguns "excessos" improvisados, como as cusparadas de sua fala doentia sobre o corpo do pai, os rasgos nas rendas do vestido de Zana, ao tentarem separá-lo de Halim, e os puxões nos cabelos de Domingas, quando tentam levá-lo para o quintal de casa.

\section{CONSIDERAÇÕES FINAIS}

Destoante dessa perspectiva, a cineasta argentina Lucrecia Martel desacredita no ato de adaptação de um romance, pois se põe convicta de que "[...] literatura não pode ser adaptada para o cinema. O que acontece é algo de outra ordem [...]" (apud FONSECA, 2015). Martel, entretanto, oferece melhor detalhamento acerca do que seria essa “outra ordem" presente da adaptação:

Nunca pensei que me interessaria por adaptações. Mas há algo fascinante em trabalhar sobre a obra de outro. Isso obriga você a entrar num universo criado por outra pessoa, que não é o mundo real. Penso que as coisas que nos 
parecem muito perturbadoras ou comoventes nos deixam num estado de alteração que você deseja prolongar. Fazer um filme é como prolongar, neste caso, um estado de alteração que me provocou esse livro. Não é ser fiel ao livro, mas ser fiel a esse estado de alteração que o livro produziu. (apud MARTÍ, 2013)

O que a diretora sugere ser a ordem diferente no trabalho de adaptação pode ser lido como o princípio de resposta à inquietação que a leitura de uma obra literária implanta no íntimo do leitor. Dessa forma, a adaptação se comporta como uma percepção da natureza da obra, como um modo de olhá-la a partir de uma perspectiva alterada, não convencional, despertada pelas inquietações provocadas pelo texto. Por esse motivo, a adaptação se filia não ao livro em si, à fidelidade para com o enredo, mas ao "estado de alteração" de quem o adapta.

Semelhante inquietação de espírito que ascende ao coração do adaptador, após entrar em contato com uma obra da literatura, é poeticamente retratada nos versos de Orides Fontela, usados na epígrafe deste estudo. Sob o título de transposição, a voz poética declara a irrefutável recriação do mundo, quando este passa a ser observado sob ângulo de visão inaugural. Como descreve a poetisa, um jardim pode se apresentar o mesmo aos olhos humanos, porém a mesma pulsão de vidaluz que lhe compõe a existência, se vista por um olhar não cartesiano, não geométrico, portanto, alterado em perspectiva, é capaz de expor outra face dessa mesma porção de natureza. Então, o poder criativo de quem vê, o seu ponto de vista, pode ampliar jardins em múltiplas cores. Tudo é uma questão de transpor o olhar.

\section{Referências}

ALICE no País das Maravilhas (Título original: Alice in Wonderland). Direção de Tim Burton. EUA: Walt Disney Pictures, 2010. 1 DVD (108 minutos). son,. color, Dolby Digital.

AMARAL, Suzana. De lugar para lugar nenhum. Entrevista concedia a Tata Amaral. (22/11/2003). Revista Trópico. Disponível em: http://www.revistatropico.com.br/tropico/html/textos/1768,1.shl. Acesso em: 08 set. 2020.

AMOR em quatro atos. Direção de Roberto Talma. Rio de Janeiro: Rede Globo. 2011. 1080i (HDTV). son., color. 
AMORIM, Marcel Alvaro de. Da tradução intersemiótica à teoria da adaptação intercultural: estado da arte e perspectivas futuras. Itinerários, Araraquara, n. 36, p.1533, jan./jun. 2013. Disponível em:

http://seer.fclar.unesp.br/itinerarios/article/view/5652/4716. Acesso em: 16 ago. 2020.

A HORA da estrela. Direção de Suzana Amaral. São Paulo: Raiz Produções

Cinematográficas; Embrafilme, 1985. 1 DVD (96 minutos); son., color, 2.680m, 24q.

A PAIXÃO de Cristo (Título original: The Passion of the Christ). Direção de Mel

Gibson. EUA: 20th Century Fox Film Corporation, 2004. 02 Discos (Blu-ray, 126 minutos) (Making of - Parte XI Maquiagem e Efeitos Visuais).

ARANTES, Silvana. Estreia de Moacyr Góes no cinema divide Gramado. Folha de S. Paulo (Ilustrada). Cinema. São Paulo, 21/10/2003. Disponível em:

http://www1.folha.uol.com.br/fsp/ilustrad/fq2108200313.htm. Acesso em: 17 ago. 2020.

BRANCA DE NEVE e o caçador. Direção de Rupert Sanders. EUA: Roth Films; Universal Pictures, 2012. 1 DVD (129 min.). son., color.

CHARTIER, Roger. A aventura do livro: do leitor ao navegador. Tradução de Reginaldo de Moraes. São Paulo: Editora UNESP, 1999. (Coleção Prismas)

DINIZ, Thaïs Flores Nogueira. Literatura e cinema: da semiótica à tradução cultural. Ouro Preto: Editora UFPO, 1999.

DOM. Direção de Moacyr Goés. Rio de Janeiro: Waner Bros Pictures; Unipar; Diler e Associados Ltda; Labo Cine; TeleImage; Quanta; BR Petrobrás, 2003. 1 DVD (91 minutos). son., color, 35mm, 2.240m, 24q, Dolby Digital.

FONSECA, Rodrigo. "A literatura não pode ser adaptada para o cinema”, diz a diretora argentina Lucrecia Martel. Site Omelete. 23/10/2015. Disponível em: https://omelete.uol.com.br/filmes/entrevista/a-literatura-nao-pode-ser-adaptadapara-ocinema-diz-a-diretora-argentina-lucrecia-martel/. Acesso em: 09 nov. 2020.

HATOUM, Milton. Dois irmãos. São Paulo: Companhia das Letras, 2006.

HUCTHEON, Linda. Uma teoria da adaptação. Tradução de André Cechinel. Florianópolis, SC: Ed. da UFSC, 2013.

LEITCH, Thomas M. Film adaptation and its discontents: from Gon with the Wind to The Passion of the Christ. Baltimore, Maryland: The Johns Hopkins University Press, 2007.

MARTÍ, Silas. Lucrecia Martel fará coprodução com o Brasil e se diz inspirada por Glauber em novo filme. Folha de S. Paulo (Ilustrada). São Paulo, 09/06/2013. Disponível em: http://www1.folha.uol.com.br/ilustrada/2013/06/1291147-lucrecia- 
martel-faracoproducao-com-o-brasil-e-se-diz-inspirada-por-glauber-em-novo-

filme.shtml. Acesso em: 09 jan. 2020.

QUARTETO fantástico (Título original: Fantastic Four). Direção de Josh Trank. EUA: 20th Century Fox Film Corporation, 2015. 1 DVD (101 minutos). son., color.

SANDERS, Julie. Adaptation and appropriation. 1. ed. London; New York: Routledge, 2006.

STAM, Robert. Introdução. In: A literatura através do cinema: realismo, magia e a arte da adaptação. Belo Horizonte: Editora UFMG, 2008. p. 17-41.

STAM, Robert. Teoria e prática da adaptação: da fidelidade à intertextualidade. Ilha do Desterro. Florianópolis, n. 51, jul./dez. 2006. p.19-53. Disponível em:

https://periodicos.ufsc.br/index.php/desterro/article/download/21758026.2006n51p19/9 004. Acesso em: 10 fev. 2020.

VEJA esta canção. Direção de Carlos Diegues. Produção de Zelino Viana e Elano de Paula, 1994. 1 DVD (104 minutos), windescreen, color.

Recebido em: 29/01/2021

Aceito em: 22/04/2021

\footnotetext{
${ }^{1}$ A primeira peça de Shakespeare adaptada, por exemplo, data de 1898. O próprio George Méliès adaptou Shakespeare para o cinema. Notórios escritores da intitulada literatura best seller também são adaptados constantemente: Stephen King, com Carrie (1976), O iluminado (1980), Conta comigo (1986), À espera de um milagre (1999) e, recentemente, It - “A Coisa” (2017); J. K. Rowling, com a série de livros Harry Potter, tornada franquia cinematográfica, e J. R. R. Tolkien, com a trilogia O Senhor dos Anéis. Fora do âmbito fílmico, a televisão trouxe Jorge Amado para as telas, com as adaptações Gabriela, Cravo $e$ Canela (1960 e 2012), Dona Flor e seus dois maridos (1998) e Tieta (1989/1990). Também Nelson Rodrigues teve seus escritos adaptados, como A morte sem espelho (1963), Engraçadinha... Seus Amores e Seus Pecados (1995) e A vida como ela é (1996).

${ }^{2}$ No original: "Adaptation and appropriation are inevitably involved in the performance of textual echo and allusion, but this does not usually equate to the fragmentary bricolage of quotation more momently understood as the operative mode of intertextuality".

${ }^{3}$ No original: "To revitalize adaptation study, we need to reframe the assumption the even the most cursory consideration of the problem forces on us - source texts cannot be rewritten - as a new assumption: source texts must be rewritten; we cannot help rewriting them".

${ }^{4}$ No original: "[...] literature creates other literature".

${ }^{5}$ As referências da filmografia que ilustra o quadro constam no final deste artigo.
} 


\footnotetext{
${ }^{6}$ Minissérie produzida a partir do romance homônimo de Milton Hatum, com roteiro de Maria Camargo e direção geral e artística de Luiz Fernando Carvalho. Ambientada na cidade de Manaus, "Dois Irmãos é um épico familiar, um drama de enormes proporções emocionais, capaz de gerar um álbum de família que espelha a própria História do Brasil, suas alegrias e seus retrocessos. Omar e Yaqub são gêmeos. Idênticos na aparência e separados pelo amor desmedido de uma mãe. $O$ épico familiar, que espelha a história do Brasil é narrado por Nael, o filho da empregada indígena da casa, Domingas". Texto disponível em: 〈http://luizfernandocarvalho.com/projeto/dois-irmaos/>. Acesso em: 15 mar. 2018, 04:41.

${ }^{7}$ Bordwell explica que a mise-en-scène engloba todos os elementos da filmagem que estão sob comando do diretor: interpretação/atuação dos atores, iluminação, cenário, sonoplastia, figurino, maquiagem, enquadramento, posição e movimento de câmera (estes três, segundo a compreensão do estudioso, voltados mais para a técnica do dispositivo do que para a composição da cena).

${ }^{8}$ Tipo de cachimbo d'água comum em países orientais e norte-africanos, utilizado para fumar tabaco aromatizado.

${ }^{9}$ Disponível em: <http://gshow.globo.com/series/dois-irmaos/>. Acesso em 15 fev. 2018, 05:54.

${ }^{10}$ Para este trabalho, assim como em outras produções, o diretor Luiz Fernando Carvalho realizou um rigoroso processo de preparação do elenco, que compreende estudos críticos do texto, palestras e longos períodos de ensaios, nos quais os atores participam ativamente da criação das personagens. Informações disponíveis em: 〈http://luizfernandocarvalho.com/projeto/dois-irmaos/\#preparacaodeelenco >. Acesso em 16 fev. 2018, 04:35.
} 